\title{
Studies on the Photoelectrochemical Cell Containing Riboflavin Redox System*
}

\author{
Nobuyuki KAMIYA and Makoto OKAWARA \\ Research Laboratory of Resources Utilization, Tokyo \\ Institute of Technology, Ookayama, Meguro-ku, Tokyo
}

Received Sept. 51968

\begin{abstract}
A photoelectrochemical cell in which the photochemical reaction of riboflavin was introduced to the anodic reaction was investigated. Four amines added as the reductant did not give any remarkable difference on the anodic polarization and amines seemed only to take part in the photoreduction of riboflavin. Buffer solutions, $\mathrm{pH}$ range of $6-12$, were used for the electrolyte. Immediate shift of the electrode potential under irradiation was observed at each $\mathrm{pH}$ and the electrode potential approached a constant value in a few minutes. The maximum current density increased with increasing $\mathrm{pH}$ of the solution. However, photodegradation of riboflavin was remarkable at high $\mathrm{pH}$ range and the limiting and optimum $\mathrm{pH}$ was shown to be 11 , at which $\mathrm{pH}$ the electrode potential of $-660 \mathrm{mV}$ vs. SCE and the maximum current density of $960 \mu \mathrm{A} / \mathrm{cm}^{2}$ were obtained. Photovoltaic effect of riboflavin took place also in the absence of amine. But the electrode potential and the maximum current density were smaller. A tentatively constructed riboflavin-quinone photoelectrochemical cell showed the open circuit voltage of $352 \mathrm{mV}$ and the current density of $80 \mu \mathrm{A} / \mathrm{cm}^{2}$ at $10 \mathrm{mV}$.
\end{abstract}

\section{Introduction}

As one of the solar batteries which convert solar energy into electrical energy, a photoelectrochemical cell in which the redox reaction of methylene blue was introduced to the anodic reaction was investigated by the authors ${ }^{1)}$. In addition to this study an attempt was made in the present paper to introduce the photochemical and the redox reaction of riboflavin (Vitamin $\mathrm{B}_{2}$ ), which plays an important role in the biological reaction, into the anodic reaction of the photoelectrochemical cell and some of the important informations were obtained.

In the presence of certain amines or sulfdes riboflavin (I) is reduced photochemically ${ }^{2) \sim 5)}$ to reduced leuco-riboflavin (II) and the amines are oxidized to various products.

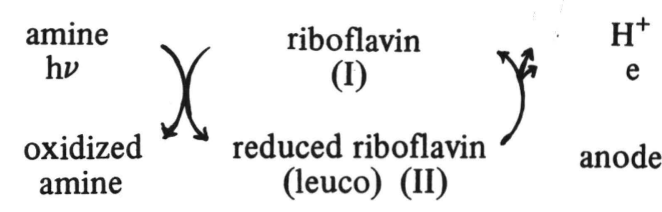

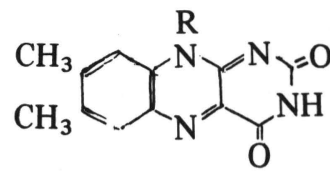

(I)<smiles></smiles>

(II)
Reduced riboflavin (leuco type, II), in turn, is readily oxidized by air to original riboflavin. Introducing the reaction system into the anodic reaction of a cell, reduced riboflavin will be

* Presented at the 8th Conference on Batteries, Kyoto, November, 1967. 
oxidized anodically followed by repeated photochemical reduction to leuco type and the energy conversion will be carried out through the cyclization.

\section{Experimental}

The cell used in studying the anodic behaviors was shown in the former paper ${ }^{1)}$. Smooth platinum plates were served for both anode and counter electrodes.

The electrode potential and the current density were recorded with a Toa Electric Ltd., EPR-2T type recorder and a Hitachi recorder QPD-33, respectively. A tungsten lamp (100V-100W) was used for the light source. The whole cell was set in a constant temperature bath and was kept at $30 \pm 1^{\circ} \mathrm{C}$. Buffer solutions, with $\mathrm{pH}$ range of 6-12, were utilized as the electrolyte (Clark-Lubs' solution: $0.2 \mathrm{M} \mathrm{KH}_{2} \mathrm{PO}_{4}$ $-0.2 \mathrm{~N} \mathrm{NaOH}$ for $\mathrm{pH} 6-8, \quad 0.2 \mathrm{M} \mathrm{H}_{3} \mathrm{BO}_{3}-0.2 \mathrm{M}$ $\mathrm{KC} 1-0.2 \mathrm{~N} \mathrm{NaOH}$ for $8-10$ and Kolthoff's solution: $0.1 M \mathrm{Na}_{2} \mathrm{HPO}_{4}-0.1 N \mathrm{NaOH}$ for $\mathrm{pH}$ 11-12). In most of the experiments concentrations of riboflavin and amine were kept $10^{-3}$ and $10^{-1} \mathrm{~mol} / l$, respectively. The amine solution was adjusted beforehand to the same $\mathrm{pH}$ of the riboflavin solution and the both solutions were introduced into the anode compartment.

After about 30 minutes of nitrogen gas bubbling, irradiation was started. In many cases, after the electrode potential reached a constant value after 1.5 hours irradiation, anodic polarization was recorded.

The whole layout of the tentatively constructed riboflavin-quinone photoelectrochemical cell was shown in Fig. 1. Platinized platinum plates were used for both electrodes. Cathode was set in the glass tube and was separated with agar film fitted at the bottom of the tube to prevent quinone solution from mixing with photochemically reduced products. The concentration of riboflavin, triethanolamine and $p$-benzoquinone were $10^{-3}, 10^{-1}$, and $10^{-1}$ $\mathrm{mol} / l$, respectively.

\section{Results and Discussion}

\subsection{Effects of $\mathrm{pH}$ Upon the Cell Per- formance}

Redox potential of riboflavin depends upon $\mathrm{pH}^{6), 7)}$ of the solution as shown with curve 5 in

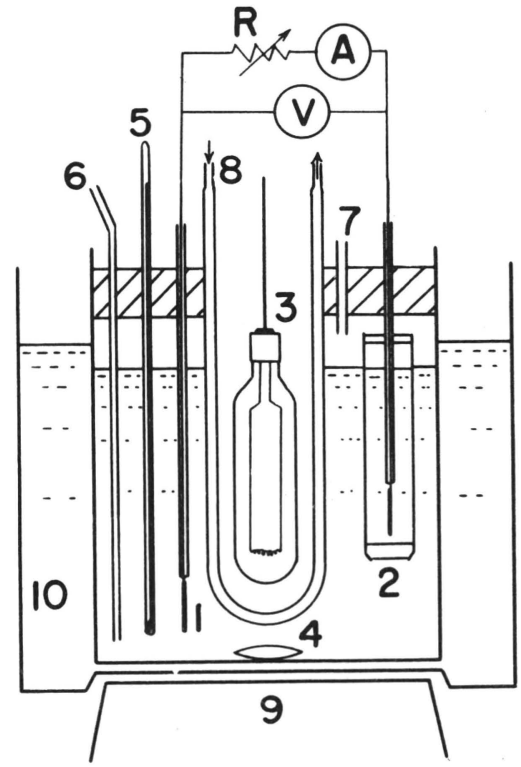

1: Anode, riboflavin solution, 2: Cathode, quinone solution, 3: Tungsten lamp, 4: Stirrer, 5: Thermometer, 6: Nitrogen gas inlet, 7: Nitrogen gas outlet, 8: Cooling jacket, 9: Motor, 10: Constant temperature bath, a: Ammeter, V: Voltmeter, R: Variable resistor.

Fig. 1 Tentatively constructed riboflavinquinone photoelectrochemical cell

Fig. 3. Moreover, the structure and the reducing power of the amine added as the reductant will be influenced with the change of $\mathrm{pH}$ of the solutions. Therefore, first of all, the shift dependence of anode potentials upon the change of $\mathrm{pH}$ was examined.

\subsection{Anode Potential Shift with Time}

Dependences of anode potential shift under irradiation upon $\mathrm{pH}$ in the presence of triethanolamine, the concentration of which was 100 times of riboflavin, and in the absence of amine were shown in Figs. 2 and 3 . The concentration of riboflavin was kept $10^{-3} \mathrm{~mol} / \mathrm{l}$.

It was observed that the electrode potential at each $\mathrm{pH}$ (about $0 \mathrm{mV}$ vs. SCE before irradiation) changed with irradiation and reached constant values within an hour in both cases, in the presence and absence of the amine. The values were larger in the presence of amine than in the absence at each $\mathrm{pH}$. In the former case, the 
anode potential exceeded the inherent redox potential of riboflavin at larger $\mathrm{pH}$ value than 8 ,

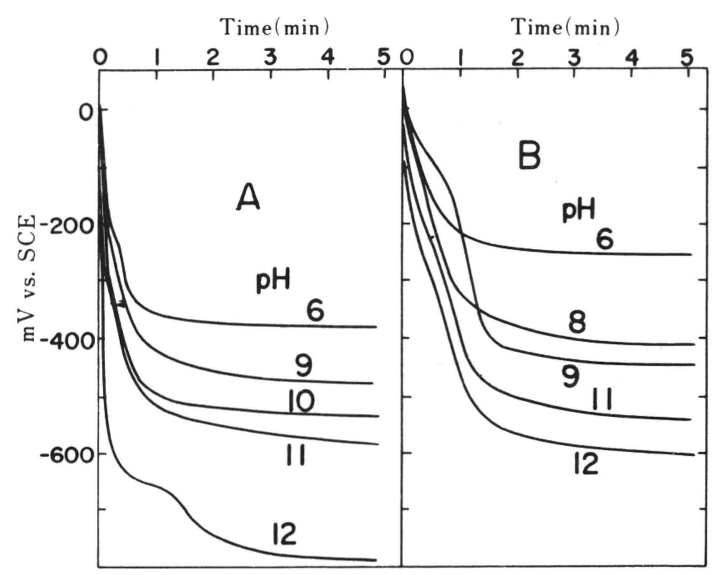

A : In the presence of amine, B : In the absence of amine.

Fig. 2 Anodic potential shift with time-(1)

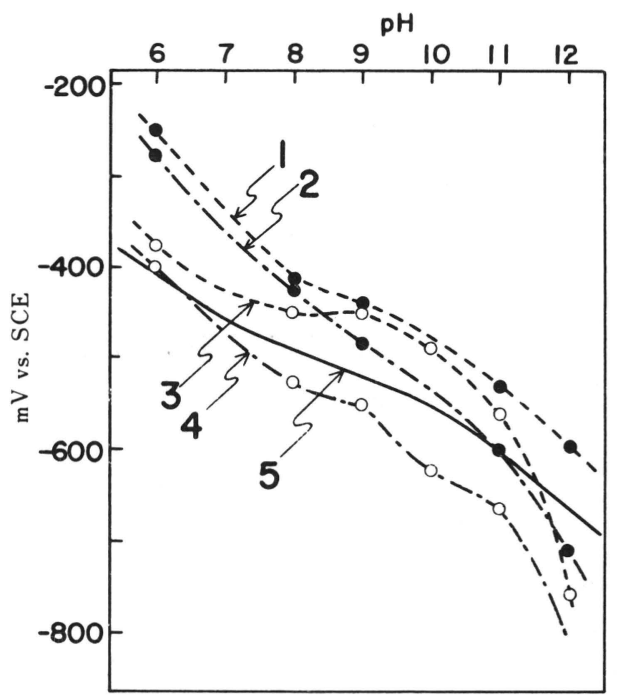

1 and $3:$ After 5 minutes irradiation, 2 and $4:$ after 1 hour irradiation, $-\mathrm{O}-:$ In the presence of amine, - : In the absence of amine, $5:$ Standard redox potential of riboflavin.

Fig. 3 Anodic potential shift with time-(2)

but did not exceed at the $\mathrm{pH}$ range of less than 11 in the latter case.

\subsection{Dependence of the Spectra Change of Riboflavin Upon Irradiation}

Visible light and ultraviolet spectra of riboflavin are shown in Fig. 4. When irradiated in the presence of amine, absorption in the visible

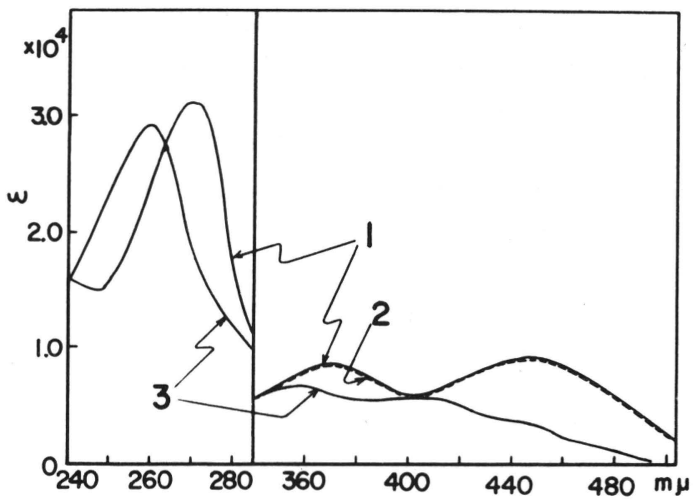

1: Original spectrum of riboflavin, 2: After twice recyclization in the presence of amine, 3: After long time irradiation in the absence amine

Fig. 4 UV spectra change

region disappeared and the wave length at maximum absorption in the ultraviolet range changed from 270 to $255 \mathrm{~m} \mu$. Original spectrum was regenerated by introducing air into the photobleached solution. In the absence of amine, such a regeneration was not observed and the absorption wave length shifted to $260 \mathrm{~m} \mu$ irreversibly. Even in the presence of amine, long time irradiation of aerated solution also changed the absorption maximum to $260 \mathrm{~m} \mu$.

Assuming that the anodic oxidation process of reduced riboflavin to form original riboflavin is similar to the oxidation with air, an attempt was made to confirm the reproducibility of reduction-oxidation process mentioned above. Repeating the photoreduction of riboflavin, aeration, deaeration, and photoreduction, the relative changes in extinction coefficient at 450 $\mathrm{m} \mu$ were represented in Table 1 (put these repeatings as recycle 1,2, and 3 ).

Table 1 UV Spectra at $450 \mathrm{~m} \mu$

\begin{tabular}{cccccc}
\hline \hline $\begin{array}{c}\text { [TEA]/[Rf] } \\
\text { pH }\end{array}$ & 9 & 100 & 11 & 12 \\
\hline Original & 100 & 100 & 100 & 83.8 \\
Recycle 1 & 94.0 & 96.5 & 102.5 & 74.9 \\
2 & 93.0 & 92.9 & 99.5 & 69.0 \\
3 & 96.6 & 89.0 & 87.3 & 53.5 \\
\hline TEA] =0 & & & & & \\
pH & 6 & 8 & 9 & 11 & 12 \\
\hline Original & 100 & 100 & 100 & 100 & 91.0 \\
Recycle 1 & 91.0 & 83.2 & 62.0 & 58.6 & 58.8 \\
2 & 88.7 & 72.7 & 43.2 & 41.2 & 43.3 \\
3 & 86.1 & 61.3 & 40.6 & 36.2 & 39.3 \\
\hline
\end{tabular}


Although good reproducibility in spectra was obtained at lower $\mathrm{pH}$ range than 11 , in the presence of amine, a considerable degradation was observed at $\mathrm{pH} 12$. In the absence of amine remarkable degradation occurred at each $\mathrm{pH}$, especially at high $\mathrm{pH}$ range.

\subsection{Dependence of Current Density Upon $\mathrm{pH}$}

The relation between the maximum current density obtained from anodic polarization and

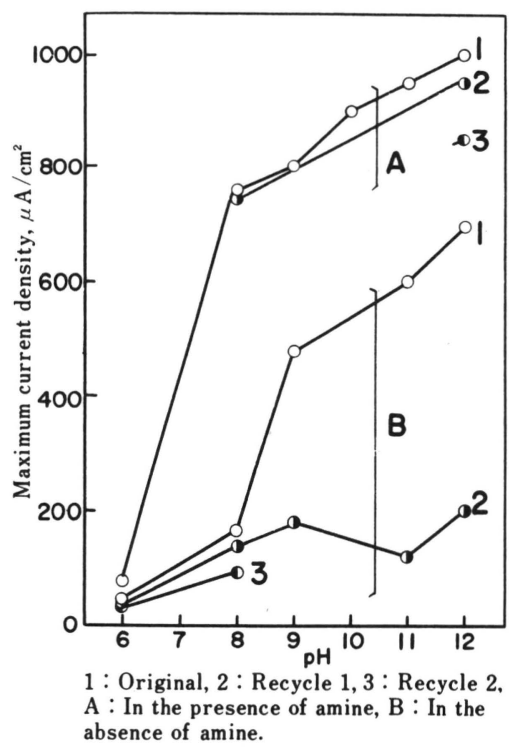

Fig. 5 Dependence of the current density upon $\mathrm{pH}$

the $\mathrm{pH}$ of the electrolytes was given in Fig. 5 . The current density increased with increasing in $\mathrm{pH}$ of the solution and this tendency was similar to that shown in the previous report ${ }^{1}$ ) concerning methylene blue photoelectrochemical cell. In the presence of amine the larger current density and better reproducibility in current density under recyclization were obtained than in the absence of amine at the same $\mathrm{pH}$.

The increase in current density in high $\mathrm{pH}$ range was considered to be due to the increase in reducing power of amine added as reductant and to the increased concentration of reduced riboflavin.

\subsection{Dependence of Current Density and Spectral Changes Upon Amine Con- centration}

As mentioned above, the maximum current density and the rate of potential shift increased with the increase in $\mathrm{pH}$ of the electrolyte. However, $\mathrm{pH} 11$ seemed to be the limiting value in order to prevent the photodegradation of riboflavin. Therefore the experiments were carried out hereafter at $\mathrm{pH} 11$.

Effects of the ratio of the concentration of amine to riboflavin upon the current density were shown in Fig. 6 . The maximum current

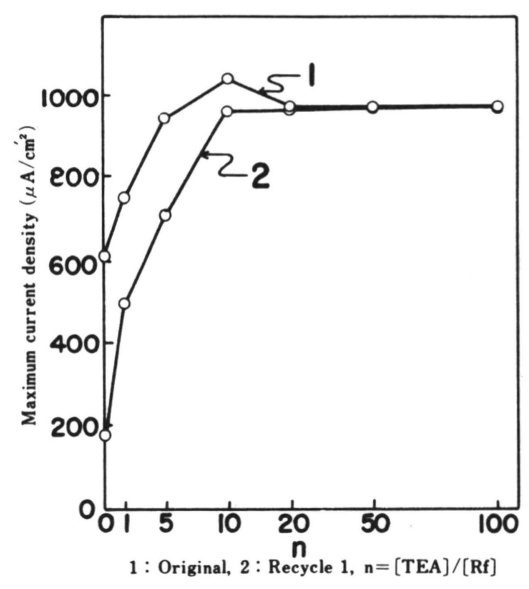

Fig. 6 Dependence of the current density upon amine concentration

density increased with increasing in the concentration of amine and reached a constant value, $960 \mu \mathrm{A} / \mathrm{cm}^{2}$, when the concentration of amine was 5 times of riboflavin. Furthermore, when $n$, i.e., the ratio of the concentration of amine to riboflavin was larger than 10 , the reproducibility of the current density in recyclization was fairly good and degradation of riboflavin was kept negligible.

\subsection{Various Kinds of Amine and the Cell Performance}

Dependence of the potential shifts and the current densities upon the various kinds of amines added as the reductant were investigated and the polarization curves were given in Fig. 7. Little changes were observed in the potential shift curves on irradiation and also in the 


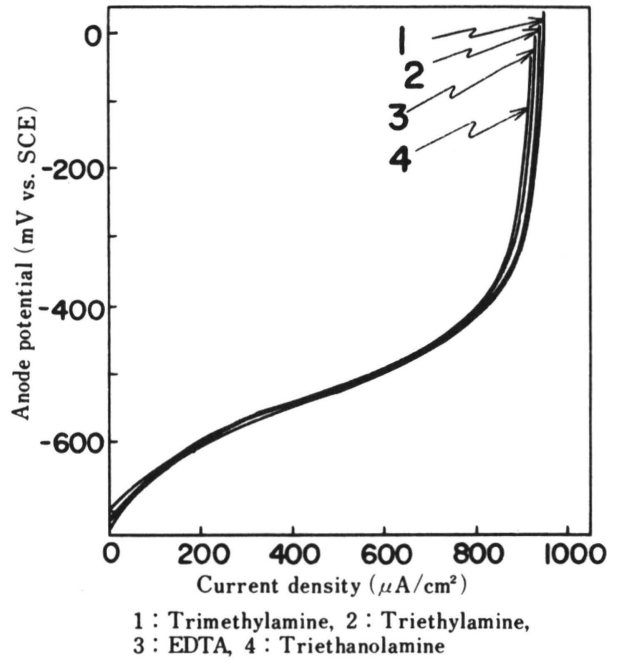

Fig. 7 Anodic polarization curves

polarization curves when triethanolamine, triethylamine, trimethylamine $(n=100$, respectively) or EDTA $(n=20)$ was added as the reductant. Therefore it was concluded that amine acted as only a reductant in photochemical reaction and had no participation in the anodic reaction.

\subsection{Photochemistry and the Cell Per- formance}

As shown above, photochemical degradation of riboflavin was observed in the absence of reductant and at the high $\mathrm{pH}$ region even in the presence of reductant. Oster ${ }^{8)}$ and other investigators ${ }^{9} \sim 12$ ) suggested in their research on the photobleaching of riboflavin in the absence of the reductant that isoalloxazine nucleus of riboflavin was first reduced with the hydrogen atoms from its side chain to produce leuco deuteroflavin followed by the scission of the side chain to give lumichrome or lumiflavin.

In our research the potential shift and the anodic polarization obtained in the absence of amine (Figs. 5 and 6) would probably be due to the leuco deuteroflavin produced by irradiation. The leuco deuteroflavin might be also an electrochemically active species as well as leuco riboflavin and gave a fairly good cell performance.

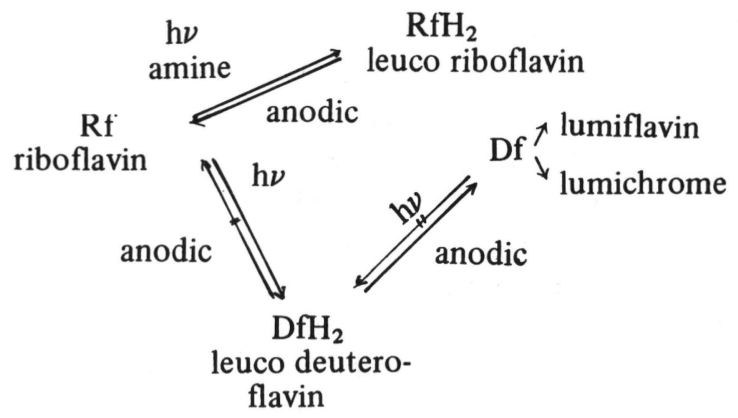<smiles></smiles>

Once the leuco deuteroflavin is converted to the oxidized form, however, the intramolecular reduction will never occur and hence only a small current density due to the remaining riboflavin might be observed at the second irradiation.

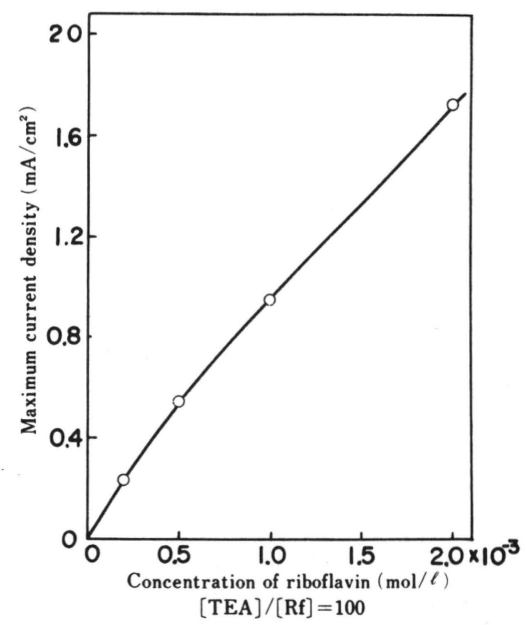

Fig. 8 Dependence of the maximum current density upon the concentration of riboflavin

\subsection{Dependence of the Cell Performance Upon the Concentration of Riboflavin} As shown in Fig. 2 and the previous paper ${ }^{1)}$ 
the rate of photoreduction of riboflavin was larger than that of methylene blue. The potential shift was fast even at the high concentration of riboflavin and the time necessary to attain a constant potential was relatively short. On the other side, the maximum current density was almost proportional to the concentration of riboflavin. As shown in Fig. 8, the current density of $1.7 \mathrm{~mA} / \mathrm{cm}^{2}$ was obtained at the concentration of $2 \times 10^{-3} \mathrm{~mol} / l$.

\subsection{Cell Performance with Platinized Plati- num Anode}

Although the smooth platinum plate was used throughout the experiments in order to maintain the condition of the surface, a platinized platinum plate was used in an attempt to get much more current density.

The anodic polarization curve after 1.5 hours irradiation was shown in Fig. 9. The current density obtained with platinized platinum electrode was far larger than that obtained with smooth platinum electrode.

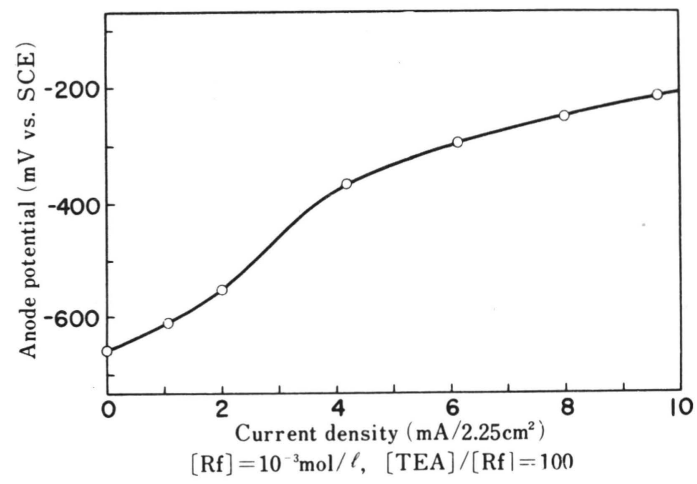

Fig. 9 Anodic polarization curve with the platinized platinum electrode

Open circuit anode potential of $-652 \mathrm{mV}$ vs. SCE and the current density of $4.22 \mathrm{~mA} / \mathrm{cm}^{2}$ at $.220 \mathrm{mV}$ were obtained (the concentrations of riboflavin and triethanolamine were $10^{-3}$ and $10^{-1} \mathrm{~mol} / l$ respectively at $\mathrm{pH} 11,30^{\circ} \mathrm{C}$ ).

\subsection{Tentatively Constructed Riboflavin- Quinone Photoelectrochemical Cell}

For the purpose of utilizing organic substances as the active species for both electrodes, riboflavin-amine solution was applied for the anode and p-benzoquinone for the cathode. The cell performance was shown in Fig.

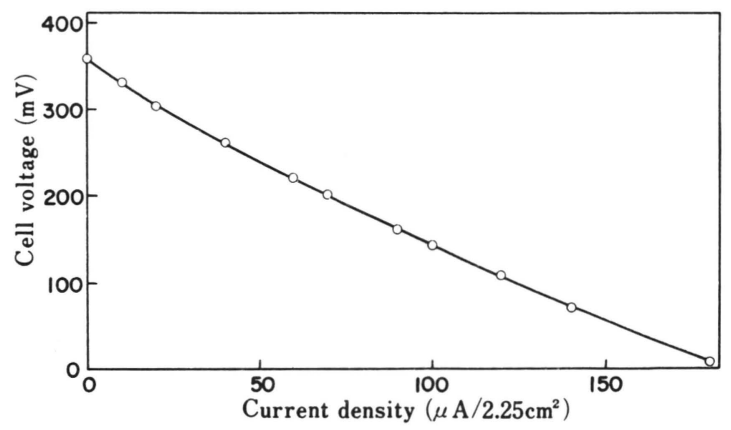

Fig. 10 Cell performance of the tentatively constructed riboflavin-quinone photoelectrochemical cell

10. The open circuit cell voltage of $352 \mathrm{mV}$ was obtained and the cell voltage lowered to $10 \mathrm{mV}$ when $180 \mu \mathrm{A}$ was taken out in this specified construction.

\section{Literature:}

1) N. Kamiya, M. Okawara, Denki-Kagaku 36, 506 (1968).

2) W. J. Nickerson, G. Strauss, J. Am. Chem. Soc. 82, 5007 (1960).

3) K. Enns, W. H. Burgess, ibid. 87, 1822 (1965).

4) J. R. Merkel, W. J. Nickerson, Biochim. Biophys. Acta 14, 303 (1954).

5) W. R. Frisell, C. W. Chung, C. G. Mackenjie, J. Biol. Chem. 234, 1297 (1959).

6) G. Strauss, W. J. Nickerson, J. Am. Chem. Soc. 83, 3187 (1961).

7) W. M. Clark, "Oxidation-Reduction Potentials of Organic Systems," p.441 (1960), Williams and Wilkins Co., Baltimore.

8) B. Holmström, G. Oster, J. Am. Chem. Soc. 83, 1867 (1961).

9) E. C. Smith, D. E. Metzler, ibid. 85, 3285 (1963).

10) W. M. Moore, J. T. Spence, F. A. Raymond, S. D. Colson, ibid. 85, 3367 (1963).

11) M. Halwer, ibid. 73, 4870 (1951).

12) P. Karrer, H. F. Meerwein, Helv. Chem. Acta 18, 1126 (1935). 